\title{
RECYCLED PET FOR RICE HUSK/POLYESTER COMPOSITES
}

\author{
I. Ahmad*, D. R. Abu Bakar, S. N. Mokhilas \\ School of Chemical Sciences and Food Technology, Faculty of Science and \\ Technology, Universiti Kebangsaan Malaysia, Bangi 43600, Selangor, Malaysia.
}

\begin{abstract}
A. Ramli
Advanced Materials Centre SIRIM Berhad, Lot 34, Jalan Hi-Tech 2/3, Kulim Hi-Tech Park, Kulim 09000, Kedah, Malaysia.
\end{abstract}

Received 11 August 2005

\begin{abstract}
Rice husks were combined with unsaturated polyester resin, synthesized from glycolysed product of poly (ethylene terephthalate) (PET) waste to form rice husk (RH)/polyester composites. PET from post-consumer soft drink bottles was recycled through glycolysis, followed by polyesterified with maleic anhydride and then cross-linked with styrene to produce a formulation for the resin. Characterizations of the synthesized resin were performed by hydroxyl, acid values and Fourier Transform Infra Red (FTIR) techniques. The effect of filler loading and surface modification of rice husks on the mechanical properties of the composites were also investigated. It has been observed that the increasing filler loading resulted in reduction of tensile strength, elongation at break and impact strength but increased tensile modulus and hardness. At similar filler loading, alkalized filler composites have higher mechanical properties.
\end{abstract}

Keywords: Unsaturated polyester resin, glycolysis, recycled PET, rice husk

\section{INTRODUCTION}

PET is extensively used in the manufacture of soft drink bottles. Due to its subsequent percentage volume in the main stream waste and its highly resistance to atmospheric and biological agents, a growing number of researches have been carried out by means of conversion of plastic waste to a value added product thus, to reclaim new applications for polymer wastes. This is accomplished through chemical recycling such as methanolysis,

\footnotetext{
* Corresponding author e-mail: gading@pkrisc.cc.ukm.my
} 
glycolysis, hydrolysis, aminolysis and ammonolysis [1], giving a wide variety of specialized products. Most of the past research concerned focused in the utilization of the product (unsaturated polyester resin, polyurethane foam, polymer concrete, coating resin and polymer composites with reinforcements) [2 - 5] when glycolysis is used.

Unsaturated polyester resins (UPRs) are one of the widely used thermosets especially in the industrial application and mostly being reinforced with fibers or fillers. However, although a small number of studies have been carried out to utilize the glycolysed product of PET into fiber reinforced composites using synthetic fibers (fiber glass mats [6] and glass roving textile [7]), no report on using natural fiber or filler was found. Hence, this study is an attempt of using natural fiber as reinforcing filler, replacing synthetic fiber which is more commonly used, using the prepared UPR as the matrix. Rice husk is chosen as the natural cellulose filler as it is one of the biomass materials abundantly available in Malaysia. However, in producing a good lignocellulosic composite, the main obstacle to be resolved is the compatibility between the filler and the matrix. The properties of the lignocellulosic composites are dominated by the interfacial interaction between the lignocellulosic filler and polymer matrix.

This paper represents a preliminary result of a research project aim to investigate the possibility of the UPR synthesized from the glycolysed product of PET waste as a matrix when rice husk $(\mathrm{RH})$ is used, in a natural filler reinforced thermoset. The effect of filler loading and alkali treatment were also investigated.

\section{EXPERIMENTAL}

\subsection{Unsaturated Polyester Resin (UPR)}

The preparation of unsaturated polyester resin is based on the esterified glycolysed product of PET with maleic anhydride and ethylene glycol. The resin was first prepared by reacting the post-consumer PET soft drink bottles (washed, dried, grind) and ethylene glycol through glycolysis in a four-necked round bottom flask of $1 \mathrm{~L}$ capacity, together with zinc acetate $(0.5 \%$ based on weight of PET) as catalyst under reflux at $180-190^{\circ} \mathrm{C}$ for $7 \mathrm{hrs}$. This is followed by a polyesterification step between the glycolysed product and maleic anhydride at $180-190^{\circ} \mathrm{C}$ for 6 hrs. Later, the liquid resin is allowed to cool down to $120^{\circ} \mathrm{C}$ and $0.45 \%$ of PET weight of hydroquinone added to prevent pre-mature curing. At $70^{\circ} \mathrm{C}$, the resin was intermixed with $35 \%$ $(\mathrm{w} / \mathrm{w})$ styrene. Chemicals and solvents are of analar grade and are used without further purification.

\subsection{Rice husk}

RH supplied by Bernas Sdn Bhd was ground and sieved into sizes of 160 - $315 \mu \mathrm{m}$ and are used without any surface treatment. $\mathrm{RH}$ was dried in an oven at $70^{\circ} \mathrm{C}$ for an overnight before being treated with $\mathrm{NaOH}$. The dried $\mathrm{RH}$ was immersed in $5 \% \mathrm{NaOH}$ solution for $1 \mathrm{~h}$ at $30^{\circ} \mathrm{C}$ then washed thoroughly with deionised water and air dried to get $5 \%$ alkali treated fillers.

\subsection{Fabricating Method}

$\mathrm{RH}$ /polyester composites containing raw untreated and treated RF were fabricated using a simple hand lay up technique. The working surface is polished and a mold-releasing agent is applied on the surface. The prepared resin were mixed with cobalt octoate (accelerator) and methyl ethyl ketone peroxide/MEKP (catalyst) at a ratio of resin: MEKP: cobalt octoate of 100: 
1.5: 0.5 and thoroughly mixed. Other samples were prepared, from $10 \%$ to $40 \% \mathrm{RH}$ as filler (v/v). All samples were cured at $60^{\circ} \mathrm{C}$ for $16 \mathrm{hrs}$ and post cured at $100{ }^{\circ} \mathrm{C}$ for another $2 \mathrm{hrs}$.

\subsection{Water absorption}

The test was conducted according to ASTM D471. Composite samples are first dried by heating in an oven at $70^{\circ} \mathrm{C}$ for about $24 \mathrm{hrs}$ weighed and then soaked in a bath of deionised water at room temperature. After $24 \mathrm{hrs}$, the composite samples are removed from water, wiped with tissue paper and weighed again. The percentage mass swell was then calculated as follows:

$$
\% \text { Water absorption }=\frac{W_{2}-W_{1}}{W_{1}}
$$

where $W_{1}$ and $W_{2}$ are the weights of the samples before and after immersion respectively.

\subsection{Mechanical testing}

Tensile testing of the specimens has been carried out using an Instron 5567 as per ASTM D638-91 at a cross-head speed of $5 \mathrm{~mm} \mathrm{~min}^{-1}$ and a gripping length of $100 \mathrm{~mm}$. Specimens were $100 \times 15 \times 3 \mathrm{~mm}$ in size. Impact strength was measured with a Digital Universal Froctoscope (Ceast) 6546/000 according to ASTM D256. The hardness measurements were taken as in ASTM D 2240-91 using Shore Scale D Durometer.

\subsection{Morphological study}

Studies on the morphology of the tensile fracture surfaces of the composite was carried out using a Philips SEM XL 30 scanning electron microscope. The fractured surface was spun coated with a thin layer of gold before characterization was done.

\section{RESULTS AND DISCUSSION}

\subsection{Characterization of the unsaturated polyester resin}

The UPR prepared was in green colored liquid as a result of the pigments in the PET bottles. At room temperature, the liquid turns to semi solid; therefore preheating (e.g. under a water bath) is needed before being used. The hydroxyl value, acid number and average of molecular weight of the resin are $26 \mathrm{mg} \mathrm{KOH} / \mathrm{g}, 22 \mathrm{mg} \mathrm{KOH} / \mathrm{g}$ and $2328 \mathrm{~g} / \mathrm{mol}$ respectively. An FTIR spectrum of the resin is shown in Fig. 1 and the corresponding peak assignments are included in Table 1.

FTIR was also used to observe the cross-linking during the curing process of the resin. FTIR spectra of the prepared resin after curing in Fig. 2 showed that the result of their heating (during curing process) diminished the bands: $780 \mathrm{~cm}^{-1}$; characteristics of $\mathrm{C}=\mathrm{C}$ vinyl (in styrene), 981 $\mathrm{cm}^{-1}$; characteristics of C-H out-of-plane bending in CHR=CHR (in polyester) and $1641 \mathrm{~cm}^{-1}$; indicative to the $\mathrm{C}=\mathrm{C}$ in polyester. Thus, suggests that cross-linking between polyester chain and styrene as cross-linkable monomer, both at their unsaturation active sites occurred. 
Table 1: $\quad$ Band assignments for the FTIR absorption of the prepared resin

\begin{tabular}{cc}
\hline Band position $\left(\mathbf{c m}^{-1}\right)$ & Assignments \\
\hline 3440 & $v(\mathrm{OH})$ \\
2958 & $v_{\mathrm{as}}\left(\mathrm{CH}_{2}\right)$ \\
1731 & $v_{\mathrm{s}}(\mathrm{C}=\mathrm{O})$ \\
1641 & $v_{\mathrm{s}}(\mathrm{C}=\mathrm{C})$ vinyl \\
1574 & $v_{\mathrm{s}}(\mathrm{C}=\mathrm{C}) \varphi$ \\
1451 & $\delta_{\mathrm{as}}\left(\mathrm{CH}_{3}\right)$ \\
1276 & $v_{\mathrm{as}}(\mathrm{C}-\mathrm{O}-\mathrm{C})$ \\
981 & $\delta(\mathrm{C}-\mathrm{H})$ \\
$871,780,732$ & $\delta(\mathrm{C}-\mathrm{H}) \varphi$ \\
700 & $\delta(\mathrm{C}=\mathrm{C}) \varphi$ \\
\hline
\end{tabular}

v: stretching; $\delta$ : bending; s: symmetrical; as: assymetrical; $\varphi$ : aromatic.

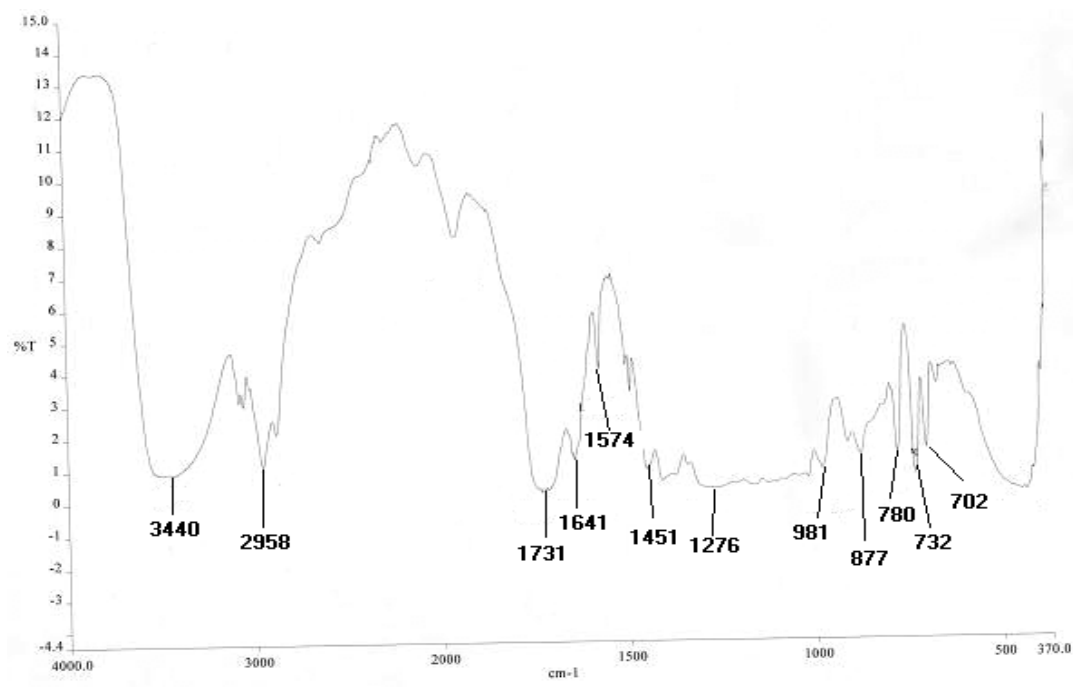

Fig. 1: $\quad$ FTIR spectrum of the prepared UPR

\subsection{Characterization of the composites}

\subsubsection{Mechanical test}

Figure 3 shows the variation of tensile strength with filler loading for treated and untreated RH. It can be seen that both systems show a decreasing trend as the filler loading increases. Other researcher [8] observed a similar trend in other lignocellulosic-filled composites. Unlike fibers that have a uniform cross section and relatively high aspect ratio, for irregular-shaped fillers such as RH, their capability to support stress-transmitted form the matrix is rather poor. Thus, the strength enhancement in the filled composite is, in general, much lower than that of fiber- 
reinforced composites. Nielsen [9] reported that in the particulate filled composites due to poor stress transfer at the filled-polymer interphase discontinuity is created which generate weak structure. Agglomeration of the filler particles and dewetting of the polymer at the interphase aggravate the situation by creating stress concentration points which account for the weakness in the composite.

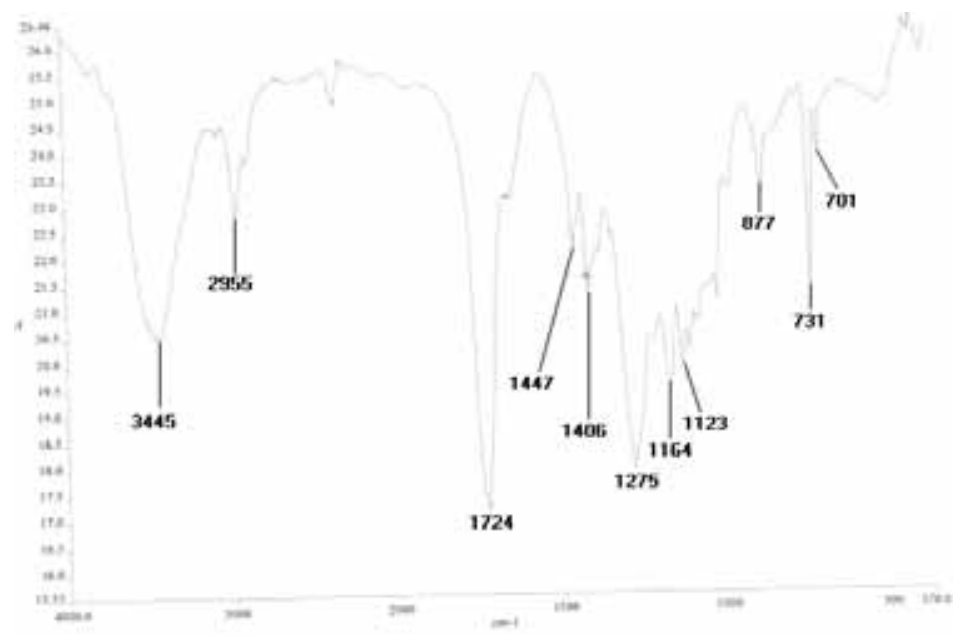

Fig. 2: $\quad$ FTIR spectrum of the prepared UPR (after curing)

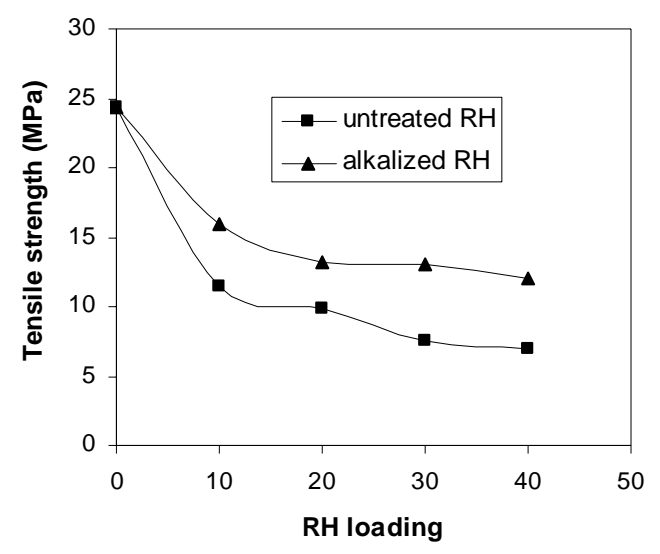

Fig. 3: Effects of $R H$ loading on the tensile strength

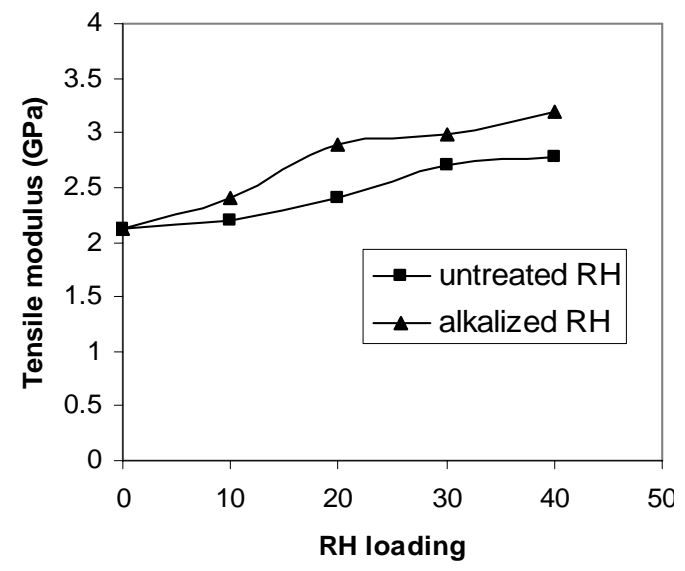

Fig. 4: Effects of $\mathrm{RH}$ loading on tensile modulus

It can also be seen in Fig. 3 that at a similar RH loading, tensile strength of alkali treated fibers is higher than the system without fiber surface treatment. The result indicates that alkali treatment results in an improvement in the interfacial bonding by giving rise to additional sites of mechanical interloacking, hence promoting more resin-fiber interpenetration at the interface [10]. The alkali treatment improves the surface adhesive characteristics by removing natural and artifical impurities, thereby producing rough surface topography. The alkali treatment also helps to improve the dispersion of filler in the matrix, led in reducing the agglomeration of the filler [11]. 
The effect of treated and untreated $\mathrm{RH}$ on tensile modulus of RH/polyester composites is shown in Fig. 4. The increase in modulus with RH loading in both systems indicates the ability of RH to impart greater stiffness to the matrix. A similar observation can be seen in Fig. 5 for hardness test results. However, at similar filler loading, polyester matrix with treated RH exhibit higher tensile modulus and hardness than the system without alkali treatment. As discussed earlier, this may be attributed to the improvement in the filler-matrix bonding, which leads to an increase in the efficiency of stress transfer from the matrix to the filler phases.

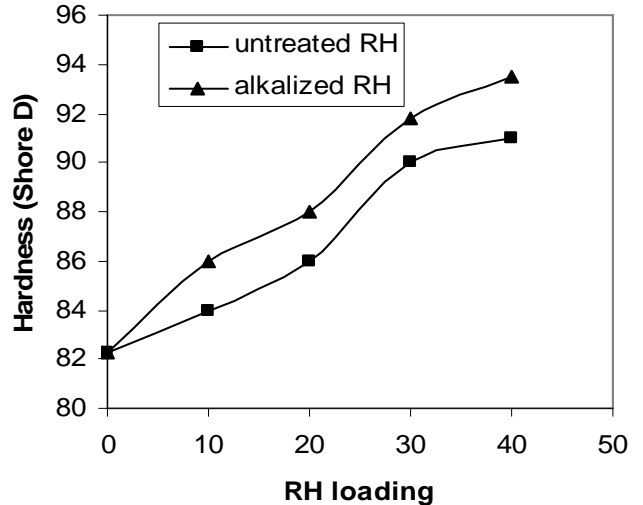

Fig. 5: $\quad$ Effects of RH loading on hardness

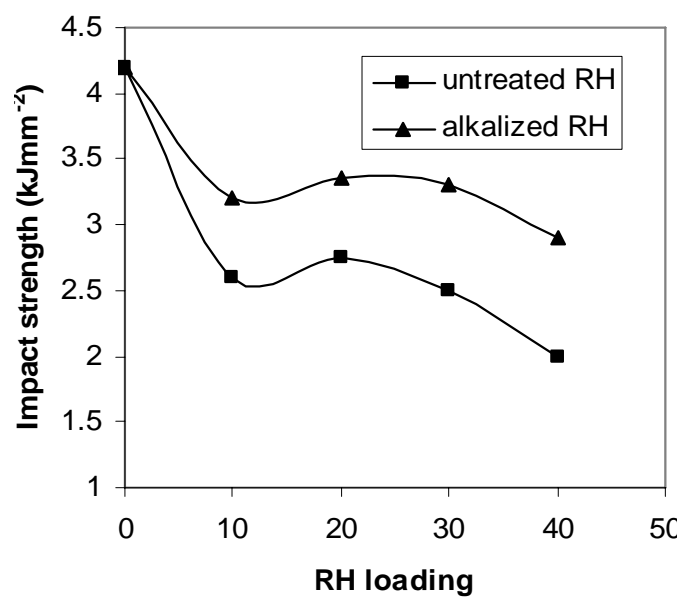

Fig. 7: Effects of RH loading on impact strength

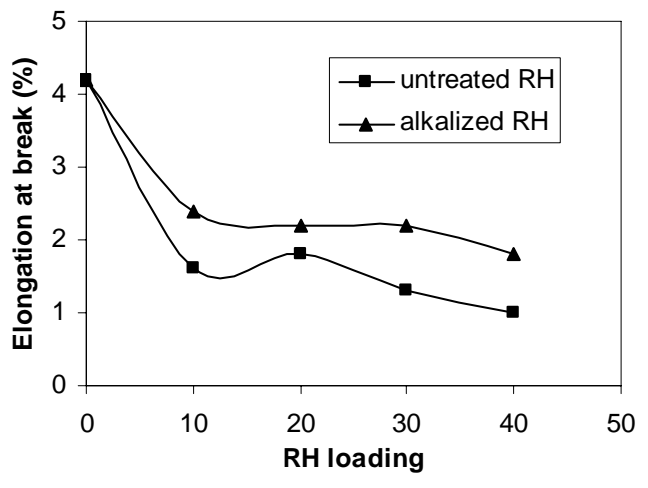

Fig. 6: $\quad$ Effects of $\mathrm{RH}$ loading on elongation at break

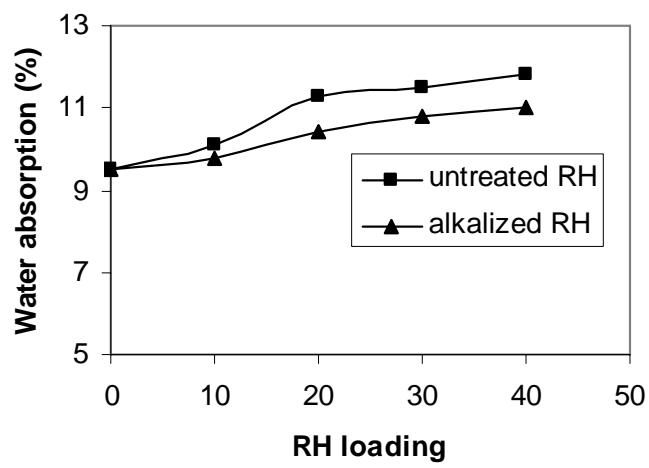

Fig. 8: Effects of $R H$ loading on water absorption

Fig. 6 shows the effect of filler loading on elongation at break of RH/polyester composites with and without alkali treatment on RH. Elongation at break showed a significant decrease with increasing filler loading which indicates hindrance by $\mathrm{RH}$ to molecular mobility or deformability of polyester matrix. However, the treated $\mathrm{RH}$ reduced this phenomenon, where the $\mathrm{RH} /$ polyester composite exhibit higher elongation at break than the similar composite without fiber surface treatment.

The effect of filler loading on the impact strength of RH/polyester with and without alkali treatment is shown in Fig. 7. It can be observed that with the introducing of RH, the impact strength decreased rapidly and then became stable after $10 \%$ filler loading. Impact strength is an 
indication of tolerability for sudden force where the composite is subjected to rapid crack propagation through the material. The crack propagation is usually initiated through $\mathrm{RH}$ particle the filled composite. Filler can absorb the energy to stop the crack propagation if the fillermatrix interaction is strong enough. The result therefore indicates that the filler-matrix is weak especially for the RH without alkali treatment.

\subsubsection{Water absorption properties}

Figure 8 shows variation of water absorption with RH loading in RH/polyester composites. As the $\mathrm{RH}$ is lignocellulosics, and therefore hydrophilic in nature, the composites made from this filler showed higher water uptake. However alkalized filler shows lower water absorption properties than that of untreated filler. With the alkali treatment, more interfacial regions are expected to be formed between the filler and the polymer matrix. Thus this would render the region stiffer and subsequently reduce the penetration by the water further.

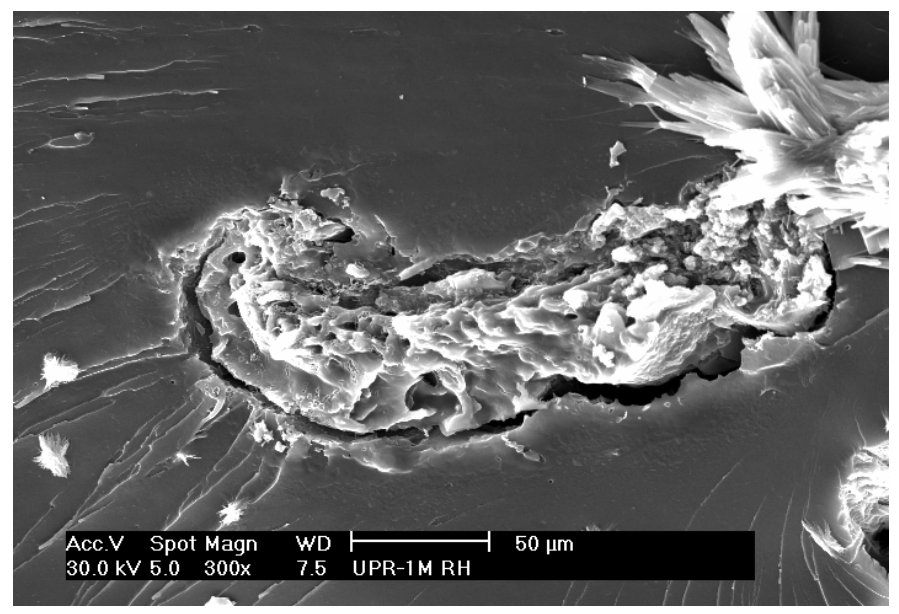

Fig. 9: $\quad$ Fracture surface of untreated RH/Polyester composites

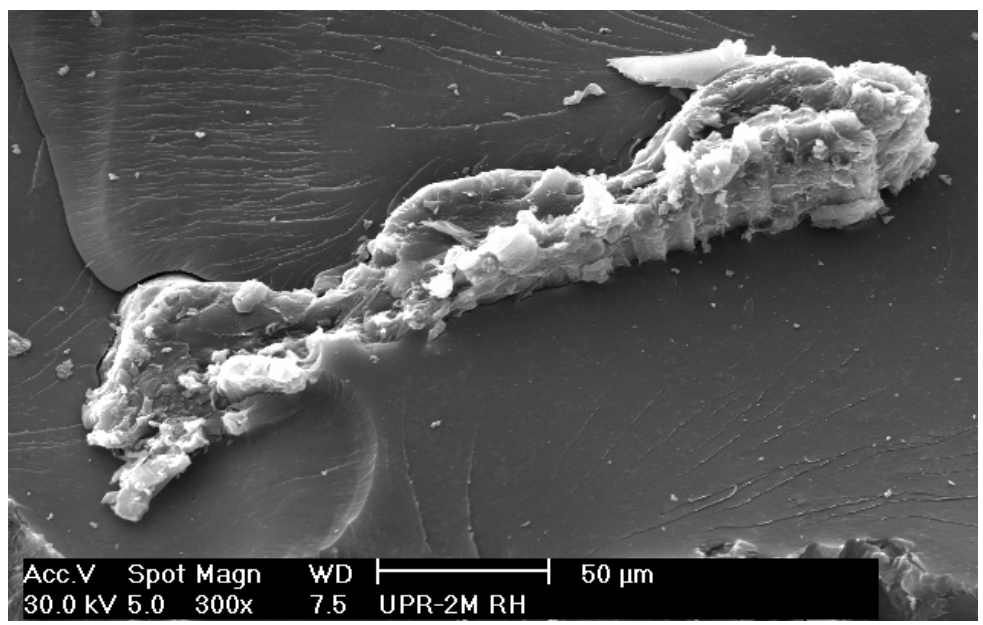

Fig. 10: Fracture surface of alkalized RH/Polyester composites 


\subsubsection{SEM analysis}

Figs. 9 and 10 show the SEM micrographs of fracture surface for RH/polyester composites without and with alkali treatment respectively. Tensile fracture surfaces in both figures clearly show that the size of RH without treatment (Fig. 9) is bigger than the size of RH after surface treatment (Fig. 10). It is believed that the reduction of filler particle sizes led in increasing the filler in contact with the matrix. The bigger size of RH could also due to the agglomeration and poor dispersion of filler in the matrix. Fig. 10 also showed that the interaction of filler-matrix is good with no crack propagation occurs at the filler-matrix interface whereas for untreated filler, there is some part of the filler, which are not completely filled with the matrix (Fig. 9).

\section{CONCLUSION}

Recycling of PET waste through glycolysis was successfully performed to obtain unsaturated polyester resin. This resin offered a function as matrix for natural fiber in a natural fiber reinforced thermoset, thus acts as a beneficial means for new product of recycled PET. The incorporation of $\mathrm{RH}$ into polyester matrix increase the tensile modulus, hardness and water absorption but decreases the tensile strength and elongation at break. Poor filled-matrix interaction and dispersion of filler are believed to be responsible for the poor ultimate properties. However, with the alkali surface treatment, the properties of RH filled polyester, synthesized from glycolysed product of poly(ethylene terephthalate) (PET) waste were improved significantly.

\section{ACKNOWLEDGEMENT}

The authors are grateful to the Ministry of Science, Technology and Innovation (MOSTI) for providing financial assistance through research grant IRPA 09-02-02-0092-EA237.

\section{REFERENCES}

1. Paschun, D. and Spychaj, T. (1997), Chemical Recycling of poly (ethylene terephthalate), Ind. Eng. Chem. Res., vol. 36, pp. 1373-1383.

2. Vaidya, U.R. and Nadkarni, V.M. (1987), Unsaturated polyester resins from PET waste: Synthesis and characterization, Ind. Eng. Chem., vol. 26, pp. 194-198.

3. Vaidya, U.R. and Nadkarni, V.M. (1988), Polyester Polyols for Polyurethanes from PET Waste: Kinetics of Polycondensation, J. Appl. Polym. Sci., vol. 35, pp. 775-785.

4. Rebeiz, K.S. (1996), Precast use of Polymer Concrete using unsaturated polyester resin based on recycled PET waste, Construc. and Build. Mater., vol. 10 (3), pp. 215-220.

5. Kawamura, C., Ito, K., Nishida, R., Yoshihara, I., and Numa, N. (2002), Coating Resins synthesized from recycled PET, Prog.in Org. Coatings, vol. 45, pp. 185-191.

6. Aslan, S., Immirzi, B., Laurienzo, P., Malinconico, M., Martuscelli, E., Volpe, M. G., Pelino, M., and Savini, L. (1997), Unsaturated polyester resins from glycolysed waste polyethyleneterephthalate: synthesis and comparison of properties and performance with virgin resin, J. Mater. Sci., vol. 32, pp. 2329-2336.

7. Radenkov, Ph., Radenkov, M., Grancharov, G., and Troev, K. (2003), Direct usage of products of poly (ethylene terephthalate) glycolysis for manufacturing of glass-fiberreinforced plastics, Eur. Polym. J., vol. 39, pp. 1223-1228. 
8. Rozman, H.D., Yeo, Y.S., Tay, G.S., and Abubakar, A. (2003), The mechanical and physical properties of polyurethane composites based on rice husk and polyethylene glycol, Polym. Testing, vol. 22, pp. 617-623.

9. Neilsen, L.E. (1974), Mechanical Properties of Polymers and Composites, Marcel Dekker, New York.

10. Mishra, S., Mohanty, A.K., Drzal, L.T., Misra, M., Parija, S., Nayak, S.K. and Tripathy, S.S. (2003), Studies on mechanical performance of biofibre/glass reinforced polyester hybrid composites, Comp. Sci. \& Tech., vol. 63, pp. 1377-1385.

11. Ishak, Z.A.M. and Bakar, A.A. (1995), An investigation on the potential of rice husk ash as fillers for epoxidizededr natural rubber (ENR), Eur. Polym., vol. 3, pp. 259-269. 